\title{
A comparative study of winds and tidal variability in the mesosphere/lower-thermosphere region over Bulgaria and the UK
}

\author{
D. Pancheva ${ }^{1,2}$, P. Mukhtarov ${ }^{1}$, N. J. Mitchell ${ }^{2}$, A. G. Beard ${ }^{2}$, H. G. Muller ${ }^{3}$ \\ ${ }^{1}$ Geophysical Institute, Bulgarian Academy of Sciences, 1113 Sofia, Bulgaria \\ ${ }^{2}$ The Department of Physics, The University of Wales, Aberystwyth, SY23 3BZ, UK \\ ${ }^{3}$ The University of Cranfield, The Royal Military College of Science, Shrivenham, Swindon, SN6 8LA, UK
}

Received: 17 January 2000 / Revised: 14 April 2000 / Accepted: 10 May 2000

\begin{abstract}
Meteor radars located in Bulgaria and the UK have been used to simultaneously measure winds in the mesosphere/lower-thermosphere region near $42.5^{\circ} \mathrm{N}$, $26.6^{\circ} \mathrm{E}$ and $54.5^{\circ} \mathrm{N}, 3.9^{\circ} \mathrm{W}$, respectively, over the period January 1991 to June 1992 . The data have been used to investigate planetary waves and diurnal and semidiurnal tidal variability over the two sites. The tidal amplitudes at each site exhibit fluctuations as large as $300 \%$ on time scales from a few days to the intra-seasonal, with most of the variability being at intra-seasonal scales. Spectral and cross-wavelet analysis reveals closely related tidal variability over the two sites, indicating that the variability occurs on spatial scales large compared to the spacing between the two radars. In some, but not all, cases, periodic variability of tidal amplitudes is associated with simultaneously present planetary waves of similar period, suggesting the variability is a consequence of non-linear interaction. Calculation of the zonal wave number of a number of large amplitude planetary waves suggests that during summer 1991 the 2-day wave had a zonal wave number of 3 , but that during January-February 1991 it had a zonal wave number of 4 .
\end{abstract}

Key words: Meteorology and atmospheric dynamics (middle atmosphere dynamics; waves and tides)

\section{Introduction}

Over the last two decades, ground-based measurements of winds made by radar systems have proved to be a powerful tool in studies of the dynamics of the mesosphere/lower-thermosphere (MLT) region. An in-

Correspondence to: D. Pancheva

e-mail: ddp@aber.ac.uk creasing element of such work has been co-ordinated studies that combine measurements made by radars at different geographical locations to investigate the spatial and temporal structure and variability of winds, waves and tides. A series of international campaigns such as the Dynamic Adapted Network (DYANA), the Mesosphere Lower Thermosphere Coupling Study (MLTCS) and the Planetary Scale Mesopause Observing System (PSMOS) have revealed that significant temporal variability occurs on short-term, intra-seasonal, seasonal and inter-annual time scales. Significant spatial variability with latitude, longitude and hemisphere is also apparent. These studies have generally involved observational campaigns of about 10 days to three months in duration.

For example, Singer et al. (1994) examined data from 14 radars recorded during the DYANA campaign of January 15 to March 15, 1990 and reported clear longitudinal differences between the prevailing winds over Canada, Central Europe, Eastern Europe and Asia. These authors also noted a close connection between the circulation of the stratosphere and the observed longitudinal structure in the MLT-region response to stratospheric warming events. An apparently related increase in MLT-region wave activity at wave periods of 8-15 days was also noted. A similar connection with stratospheric processes was noted by Pancheva and Mukhtarov (1994), who related wave activity at MLT heights to the presence of a strongly amplified planetary wave number 1 at the $30 \mathrm{hPa}$ pressure level during the winter 1991/1992. Portnyagin et al. (1994) also examined the DYANA campaign data used by Singer et al. (1994) and concluded that the significant differences observed between monthly mean tidal parameters measured by the various radars could be explained by latitudinal and longitudinal structure in the tidal wind fields. In addition, well-defined fluctuations in tidal parameters over periods of 2-3 weeks were found to be typical of all the observational sites.

Characterising the global structure of the MLTregion tidal and planetary wave fields has also been a prime objective of the MLTCS programme (e.g. 
Forbes, 1990; Manson et al., 1994; Deng et al., 1997), and as part of MLTCS a series of 10-day global observational campaigns have been conducted to study MLT-region coupling processes involving tides and planetary waves.

In this work, we consider the variability of winds and tides measured by two, very similar, meteor radars recording MLT-region winds; one sited near Yambol, Bulgaria and recording winds near $\left(42.5^{\circ} \mathrm{N}, 26.6^{\circ} \mathrm{E}\right)$ and the other sited near Sheffield in the UK and recording winds near $\left(54.5^{\circ} \mathrm{N}, 3.9^{\circ} \mathrm{W}\right)$. A detailed statistical study of the variability of tides over the UK has been presented elsewhere (Beard et al., 1999b), and so the focus of the work presented here is not to investigate tidal variability over each station in isolation, but rather to investigate the degree to which the variability over each station is correlated. In other words, we seek to assess some simple measure of the spatial coherence of the tidal variability occurring over both stations.

The data are for the 18-month interval January 1991 to June 1992. The similarity in the two radars' modes of operation greatly reduces any biases that might otherwise complicate inter-comparisons between the two data sets. We therefore will make direct, statistical comparisons involving observations over the entire 18 months for which data are available from both radars. Such long-term studies provide a valuable complement to the results of short-term observational campaigns of the type discussed already.

The data used in this study covered areas of the northwestern and southeastern parts of Europe. The $30.5^{\circ}$ longitudinal difference between the stations allows some investigation of the zonal wave numbers of planetary waves and the longitudinally dependent, long-term dynamical processes associated with stratospheric warmings and/or equinoctial transitions.

Three particular topics are addressed in this work. In Sect. 3.1 the longer-term seasonal and intra-seasonal variations in the background wind and tides are considered. In Sect. 3.2, the shorter-term, day-to-day variability of tides in particular is considered. This latter variability is now believed to include a substantial contribution that arises from a non-linear interaction between tides with planetary waves. In this process, which appears to function most conspicuously with the semidiurnal tide, a non-linear interaction generates a family of "secondary waves", some of which have frequencies equal to the sum and difference of the frequencies of the planetary wave and tide (Teitelbaum and Vial, 1991). Because planetary waves have much lower frequencies than the tides, these secondary waves have frequencies near tidal frequencies and may beat with the tide, modulating the tidal amplitude at the planetary-wave period (e.g. Teitelbaum and Vial, 1991; Rüster 1992, 1994; Mitchell et al., 1996; Clark and Bergin, 1997; Kamalabadi et al., 1997; Beard et al., 1999a; Pancheva, 2000). Other studies have recently suggested that similar interactions may also occur between different members of the planetary-wave field (Jacobi et al., 1998; Pancheva et al., 2000). Finally, in
Sect. 3.3 the zonal wavenumbers of some of the larger amplitude planetary waves observed are determined.

\section{Measurements and data analysis}

The meteor radar at Yambol operated at 27.7 MHz with a pulse repetition frequency of $100 \mathrm{~Hz}$, and a peak power of about $10 \mathrm{~kW}$. The radar operated without height finding and so provided a measure of winds across the meteor region with a weighting reflecting the distribution of meteor counts, which is believed to be strongly peaked at a height near $90 \mathrm{~km}$. The winds derived from such systems are thus usually taken to represent an average over perhaps 6-10 $\mathrm{km}$ centred on this height. The measurements were obtained by sounding simultaneously in four geographical directions, however because of disturbances in two of them (east and north) during most of the day-time after April 1991, only the measurements of the western and southern antennae were used in processing and analysing the data. This fact is a reason why the level of noise for the measurements after April 1991 is higher than the previous ones when the north and south measurements were averaged together to produce a single data set corresponding to the meridional component of the neutral wind and similarly, the east and west measurements produce a single zonal component. The measurements of individual meteor drift velocities were averaged to produce hourly estimates of horizontal zonal and meridional winds. The main features of the monthlymean wind regime in the MLT region above Bulgaria have been described by Pancheva and Mukhtarov (1994, 1996).

The VHF meteor radar located near Sheffield operated at $36.3 \mathrm{MHz}$ with a pulse repetition frequency of $300 \mathrm{~Hz}$ and a peak power of about $10 \mathrm{~kW}$. The transmitted power was directed NW and SW in two narrow low-elevation beams. No height determination was employed during the time considered in this work. The hourly values of zonal and meridional velocities are obtained by the simple procedure described by Beard et al. (1999a).

The time series of hourly zonal and meridional winds from each radar were then subjected to a common analysis. For each 24-h section of data, a least squares best-fit analysis determined the amplitude and phase of the 8-, 12- and 24-h tides and mean wind. The derived characteristics are assigned to the centre of the section of data. No fit was attempted if less that $16 \mathrm{~h}$ of data were present in any $24-\mathrm{h}$ segment. Then the 24 -h segment was incremented in one-hour steps through each time series producing hourly estimates of these quantities. To estimate the confidence intervals we assume that the residual error can be described as Gaussian white noise and then the Student $t$-test is used to estimate the confidence intervals. This procedure is described in detail by Mukhtarov and Pancheva (1993). To obtain the hourly values of the tidal characteristics and prevailing wind we usually have to cope with the problem of filling the gaps. When the length of the 
gap is small, or in each 24-h segment the total missing points are smaller than 8 and there are no more than three successive ones, we simply used the periodical filling, made from the program for the analysis of hourly values of data, that can be used to fill the small gaps simultaneously. When the length of the gap is longer than $24 \mathrm{~h}$ we use a special procedure, convenient for filling the gaps in time series that have well-expressed periodical components (such as tides, for example). The idea is that first, we carefully investigate the data neighbouring the gap intervals using time periods at least twice as long as the gaps and determine the mean values and characteristics of one or two of the strongest periodical components. Then we fill the gap with these mean values, bearing in mind that the variance of the gap has to be similar to those of the neighbouring intervals. When the semidiurnal tides are not well expressed in the hourly values of data we used a leastsquared fitting of the neighbouring values using second degree polynomials with exponentially decreasing weights.

Spectral studies were undertaken using the "correloperiodogram" type of periodogram analysis. This method is described by Kopecky and Kuklin (1971) and allows assessment of the amplitude, phase and significance level of the signal at particular frequencies where the frequency considered can be incremented in steps of arbitrary size. The main advantage of this method is that it can obtain high-resolution spectral estimates in a frequency range of interest by use of arbitrarily small frequency steps.

Data of the type considered here does not obey the stationarity criterion for time series analysis; i.e. the population of waves present changes over the duration of the time series. In such cases conventional Fourier transforms cannot follow the temporal evolution of such a wave field and an incremented Fourier window or a wavelet transform must be used. Here we will apply a wavelet analysis.

Wavelet transforms are becoming a favoured tool for analysing time series in which the assumption of stationarity does not hold (Daubechies, 1990). By decomposing the time series into time-frequency space the wavelet transform is able to determine both the constituent frequencies and how those frequencies vary in time, producing a two-dimensional time-frequency image (Torrence and Compo, 1997). In contrast to the Fourier transform which spreads information about the localised wave events over all scales in the Fourier space (Wernik, 1996).

The analysis presented here uses the continuous Morlet wavelet, which consists of a plane wave modulated by a Gaussian envelope. The non-dimensional frequency, which gives the number of oscillations within the wavelet itself, is set to be six to satisfy the admissibility condition (Farge, 1992). The Morlet wavelet was selected because of its simplicity and resemblance to the modulated planetary-wave "packets", frequently observed in the neutral wind.

A refinement of this analysis is used to investigate any periodicities simultaneously present in the time series from both sites. In this particular case, we apply a cross-wavelet analysis, which works as follows. For two time series $X$ and $Y$, with wavelet transforms that are, respectively, $W^{X}(a, b)$ and $W^{Y}(a, b)$, one can define the cross-wavelet spectrum as: $W^{X Y}(a, b)=W^{X}(a, b) \times$ $W^{Y *}(a, b)$, where * denotes the complex conjugate. The cross-wavelet spectrum is thus complex and the crosswavelet power can be defined as $\left|W^{X Y}(a, b)\right|$, and serves as an indication of the strength of an oscillation simultaneously present in both time series.

\section{Results}

\subsection{Long-term neutral wind and tidal variations}

Figure 1a presents zonal winds over Bulgaria (solid line) and the UK (dashed line). This line convention is used in all subsequent figures. A 5-day running mean has been used to smooth each time series. Both time series display
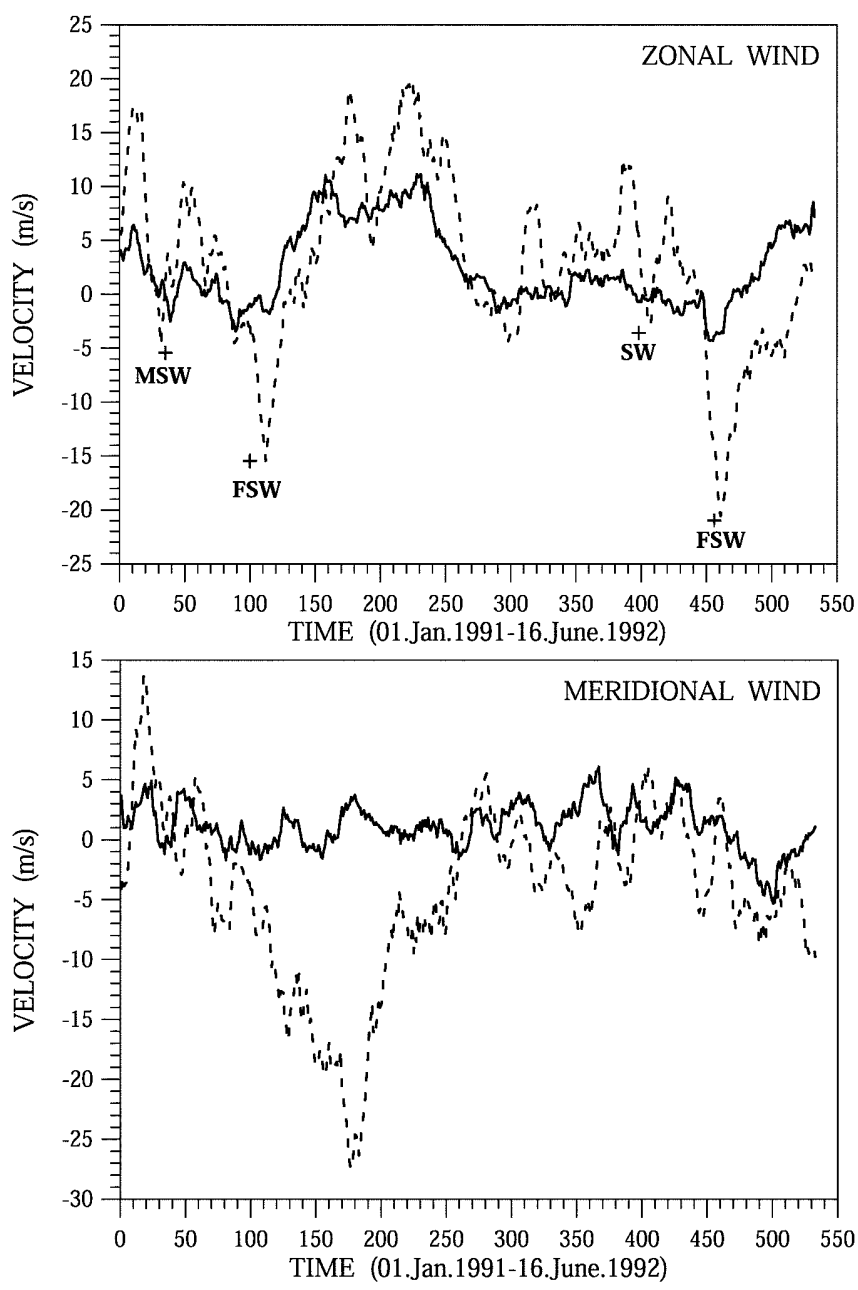

Fig. 1. a Mean zonal and $\mathbf{b}$ meridional winds over Bulgaria (solid line) and the UK (dashed line) for January 1, 1991 and June 16, 1992. The data have been smoothed by a 5-day running mean. The time of the major stratospheric warming in 1991 is marked as $M S W$, the final stratospheric warmings in 1991 and 1992 as FSW and the strong minor warming in late January 1992 as $S W$ 
a generally similar seasonal behaviour, although the magnitude of the changes over the UK is greater than over Bulgaria. The cross-correlation function calculated from the daily values of zonal winds has a maximum value of 0.70 at a lag of +8 days, i.e. on average the changes in the zonal wind over Bulgaria occur before those over the UK.

There are clear responses over both stations to the major stratospheric warming occurring over Northern Europe during 26-27 January, 1991, (Naujokat et al., 1991) and marked MSW in the figure. The reaction of the zonal wind over the UK is particularly strong to this event, where the zonal wind changed from $+17 \mathrm{~m} \mathrm{~s}^{-1}$ to $-5 \mathrm{~m} \mathrm{~s}^{-1}$. Similarly, there is a clear response in the UK data to the strong minor warming in the second half of January 1992 (Naujokat et al., 1992), marked SW on the figure. The spring transitions in 1991 and 1992, each preceded by a final stratospheric warming, marked FSW in the figure, are also clear over both stations, but the magnitude of the changes over the UK are more than four times larger than those over Bulgaria.
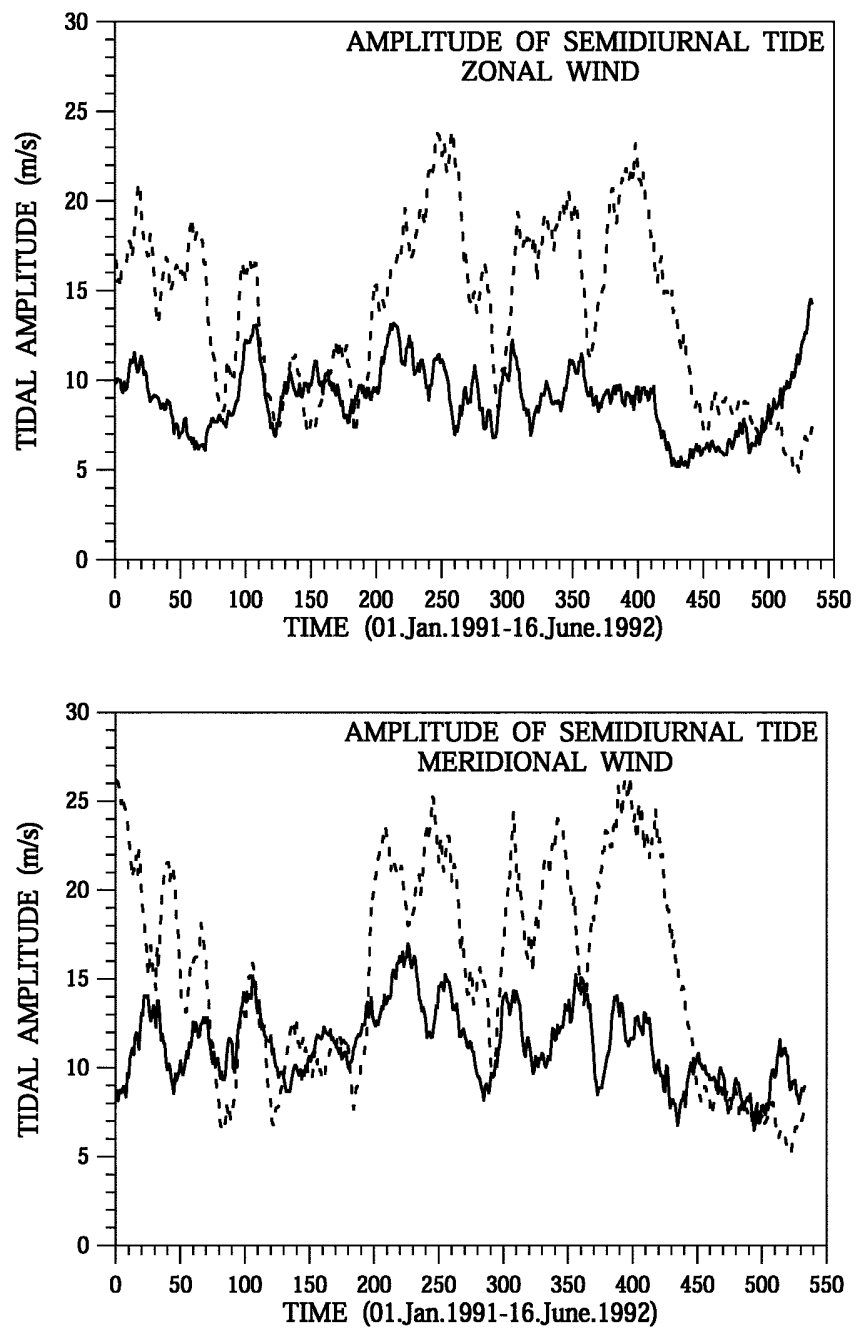

(a)
Figure $1 \mathrm{~b}$ presents the corresponding meridional winds. In contrast to the winds over the UK, the meridional wind over Bulgaria is generally very weak, and has little clear seasonal course. The cross-correlation coefficient is 0.30 at a lag of +8 days, and is attributable mainly to the second half of the interval studied, when not only the seasonal course but also the long-term variations are more similar.

Figure 2 shows the amplitudes (Fig. 2a) and phases (Fig. 2b) of the zonal and meridional components of the semidiurnal tides, again smoothed by a 5-day running mean. The figures reveal that, whilst the tidal amplitudes are generally much larger over the UK, there are often distinct similarities between the two time series on seasonal and monthly time scales. The maximum crosscorrelation coefficients and lags, calculated from the daily values of the amplitude in the zonal and meridional data, are respectively: $0.45 ;+8$ days and $0.52 ;+7$ days. The correlations are not so strong as there are time intervals, when the day-to-day variations in the amplitudes of semidiurnal tides are very different in the both
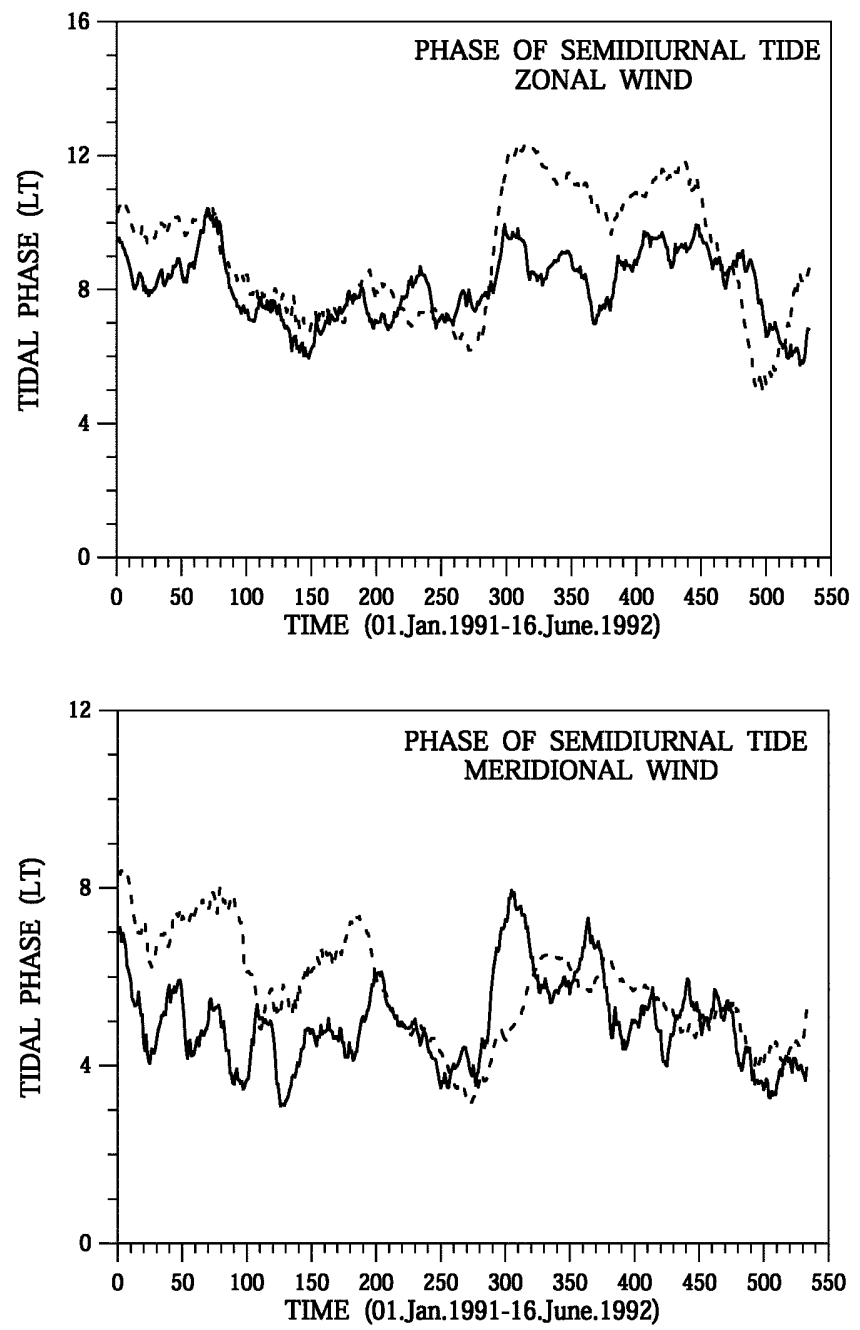

(b)

Fig. 2. a The amplitude of the semidiurnal tide over Bulgaria (solid line) and the UK (dashed line) for zonal (upper panel) and meridional (lower panel) components. The data have been smoothed with a 5-day running mean. b As a, but for tidal phases 
sites. Such intervals are: for the zonal component between day number $40-80$ and $300-350$, and for the meridional one, the first 50 days and between 200-250 and 330-380. The mean amplitude of the semidiurnal tide over the UK is on average about 1.5 times larger than over Bulgaria, in general agreement with other observations which indicate decreasing amplitudes as one moves from high to lower latitudes (e.g. Portnyagin et al., 1994). The comparison between the mean seasonal amplitudes of the semidiurnal tide in the both sites, described in detail by Beard et al. (1999b) and Pancheva and Mukhtarov (1996), confirms the new result for the seasonal variation of the tides, obtained by Manson et al. (1999) on the basis of six MF radars for the interval 1990-1997. The monthly mean values of the amplitude over both stations are also in general agreement with the theoretical model of Forbes and Vial (1989).

The correlation between the phases of the semidiurnal tide above the two sites is also quite high: 0.73 at a lag of 0 days for the zonal component and $0.46 ;+7$ days for the meridional component. The seasonal course of the phases, particularly for the zonal wind, is in good agreement with the Forbes and Vial (1989) model, as well as with other observations (Portnyagin et al., 1994; Manson et al., 1999). The results clearly demonstrate both the latitudinal dependence of the semidiurnal tidal phase and the expected 3-h phase difference between zonal and meridional components. However, it should be noted that in some, mainly summer, periods this difference deviates considerably from $3 \mathrm{~h}$ (Fig. 2b), which may be an indication of significant variation in the semidiurnal tidal modes present during these periods (Portnyagin et al., 1994).

The results of an identical analysis for the diurnal tide are presented in Fig. 3a, b. The amplitudes (Fig. 3a) and phases (Fig. 3b) of the diurnal tides over both stations are again smoothed by a 5-day running mean. The seasonal behaviour of the diurnal tide is much less well defined over both stations than is the case for the
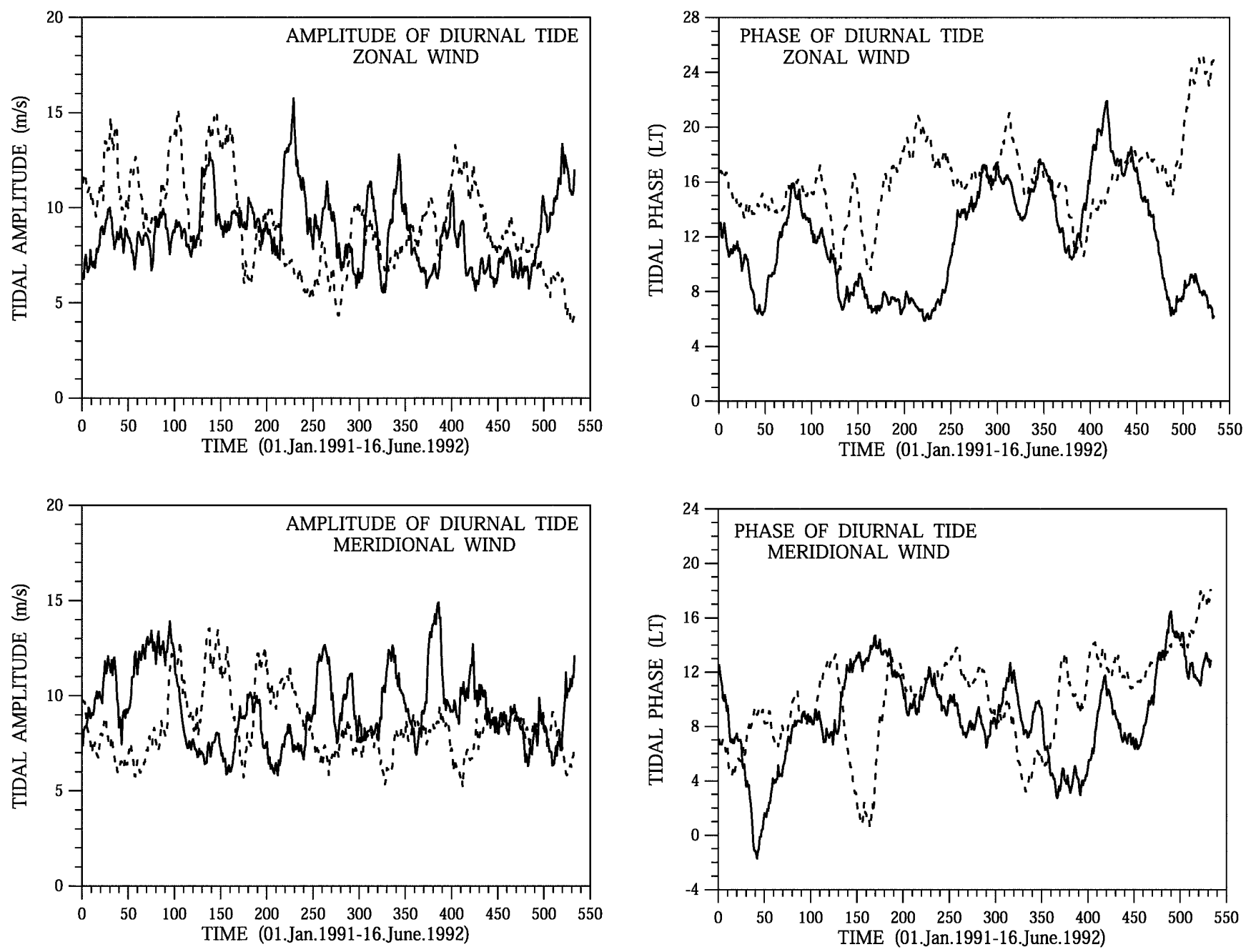

(a)

(b)

Fig. 3. a The amplitude of the diurnal tide over Bulgaria (solid line) and the UK (dashed line) for zonal (upper panel) and meridional (lower panel) components. The data have been smoothed with a 5-day running mean. b As a, but for tidal phases 
semidiurnal tide, although in the zonal winds over the UK maximum amplitudes in winter and minimum amplitudes in early summer are apparent. The correlation between the amplitude time series over the two sites for the zonal component is quite low at 0.18 at a lag of +4 days, while that between the amplitudes of the meridional components is $-0.58 ;-11$ days. In this latter case, the negative correlation and lag appears to be due to a number of strong fluctuations in amplitude that occur almost in antiphase (Fig. 3a, lower panel). Considering the phases, the cross-correlation between the two sites is $-0.27 ;+5$ days for the zonal component and $0.31 ;-10$ days for the meridional component. The negative correlation again appears to be due to the strong oscillations occurring in near antiphase as noted. The results presented in Fig. 3a, b are difficult to clearly interpret as the diurnal tide may have a rather short wavelength, so that part of its variability may be due to height uncertainties because of using the meteor neutral wind measurements without height finding.
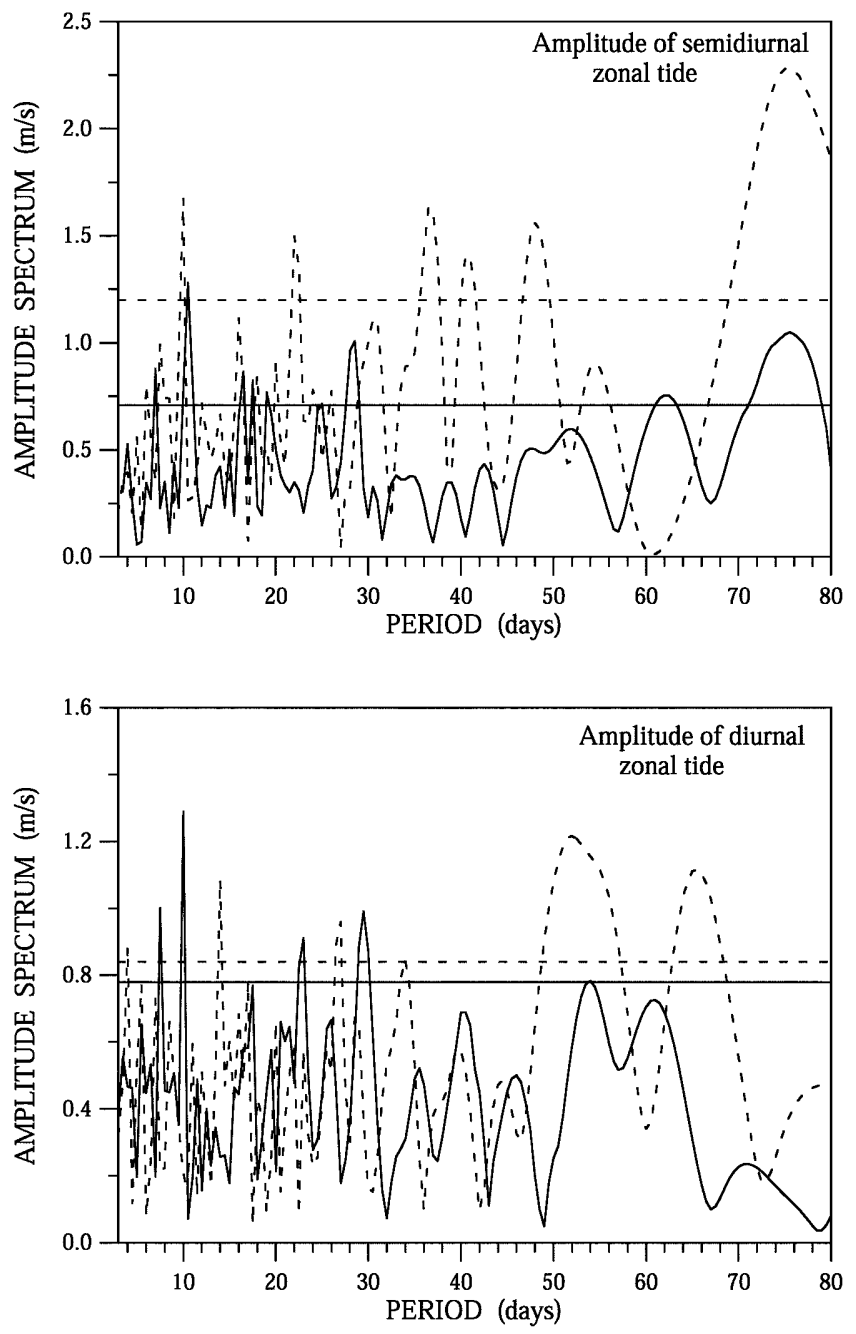

(a)
A conspicuous feature of the data presented in Figs. $2 \mathrm{a}, \mathrm{b}$ and $3 \mathrm{a}, \mathrm{b}$ is the presence of large-scale fluctuations in amplitude and phase with periods of order one month or longer. For instance, during winter 1991/2, the amplitude of the meridional component of the semidiurnal tide over the UK (Fig. 2a, lower panel) fluctuates between about $8 \mathrm{~m} \mathrm{~s}^{-1}$ and $25 \mathrm{~m} \mathrm{~s}^{-1}$, whilst the meridional amplitude of the diurnal tide over Bulgaria fluctuates from about $7 \mathrm{~m} \mathrm{~s}^{-1}$ to about $15 \mathrm{~m} \mathrm{~s}^{-1}$ at the same time (Fig. 3a, lower panel).

To further investigate such variability, a correloperiodogram analysis was applied to the complete hourly time series of both diurnal and semidiurnal tidal amplitudes and phases to determine the spectral composition of the variability over the period range 3-80 days. The results for the zonal wind components are presented in Fig. 4a, b and for the meridional components in Fig. 5a, b. To aid interpretation, the results are presented in terms of amplitude against period (rather than frequency). Again, in all cases the solid lines denote
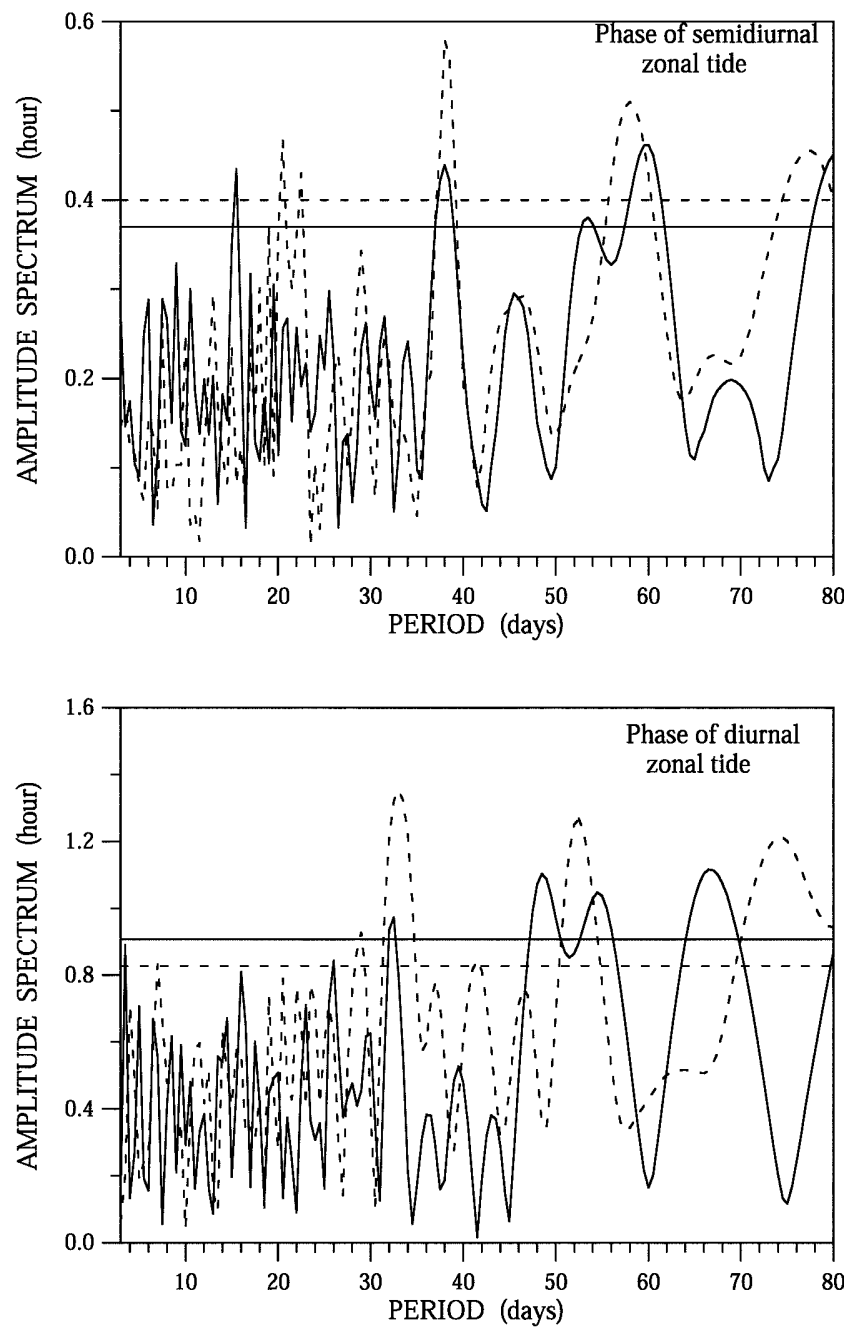

(b)

Fig. 4a, b. Spectra of a semidiurnal (upper) and diurnal (lower) zonal tidal amplitudes for tides over Bulgaria (solid line) and the UK (dashed line). The horizontal lines indicate the $95 \%$ confidence limit of each spectrum. b As a, but for tidal phases 

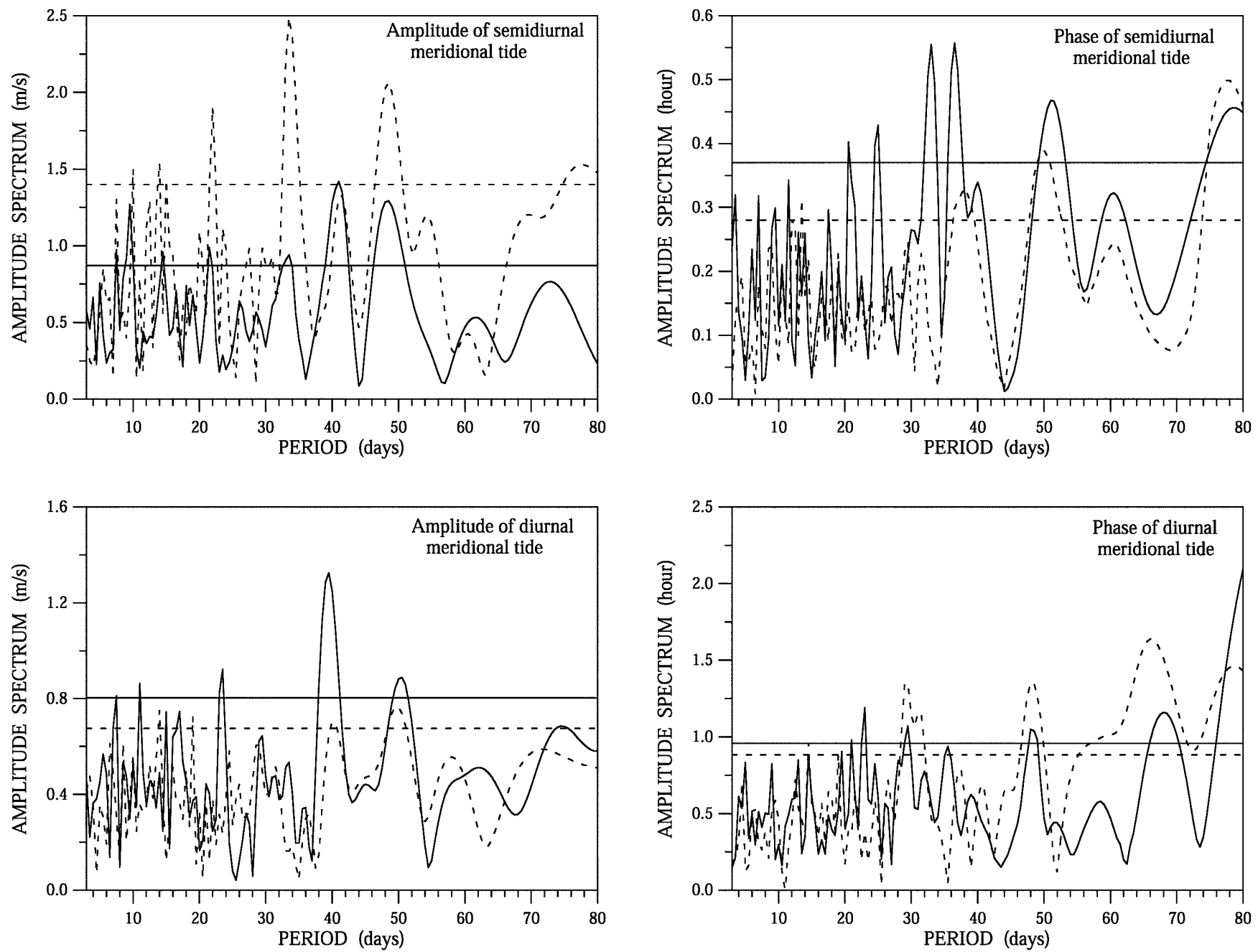

(a)

(b)

Fig. 5a, b. As Fig. 4, but for meridional components

data recorded over Bulgaria and the dashed lines denote data recorded over the UK. In each case, the $95 \%$ confidence limit is represented by the horizontal line.

In this section, we are concerned with long-term and intra-seasonal variability, and so will consider only spectral peaks in the period range 30-80 days. Shorterterm variability will be addressed in Sect. 3.2.

The zonal wind data of Fig. 4a reveals that there are significant fluctuations in the zonal component of the amplitude of the semidiurnal tide at periods near 38, 42, 48 and 75 days over the UK, and at periods of about 62 and 75 days over Bulgaria. In the diurnal tide over the UK, fluctuations in amplitude occur above the 95\% confidence level at periods of about 52 and 65 days, but over Bulgaria, no peaks exceed the $95 \%$ confidence level.

Figure $4 \mathrm{~b}$ shows that substantial fluctuations in the phase of the zonal component of the tides also occur on intra-seasonal time scales over both sites. In the case of the semidiurnal tide there are fluctuations in tidal phase above the $95 \%$ confidence level over both sites at periods of about $38,58-60$ and $78-80$ days. In the case of the diurnal tides, significant fluctuations are present in the tidal phases over both sites at periods of about $32-33$ and 50 days.

The corresponding results for the meridional components of the tides are presented in Fig. 5a, b. As might be expected, the spectra of meridional amplitude fluctuations for the semidiurnal tide over the UK shows peaks at periods very similar to those exhibited in the zonal component, namely, 35, 42, 48 and 78 days. However, in the data recorded over Bulgaria, there are now also significant fluctuations at periods of about 34 , 42 and 48 days. In the case off the diurnal tides, the data from both the UK and Bulgaria reveal significant peaks at periods of about 40 and 50 days.

The spectra of the phases of the meridional tidal components are presented in Fig. 5b. The semidiurnal phases reveal fluctuations at periods of $34-38,52,60$ and 78 days over both the UK and Bulgaria. These periods are close to those apparent in the zonal component of this tide (Fig. 4b). The diurnal tide 
recorded over both sites has significant fluctuations at periods of about 30-32, 48, 64-68 and 78-80 days, again similar to those apparent in the zonal component of the tide (Fig. 4b).

It is noteworthy that in these comparisons between the data recorded over the UK and Bulgaria, the significant peaks in the spectra of tidal amplitudes and phases at periods from 30-80 days are often very closely related, except perhaps in the case of the zonal component amplitudes. Given that these are two entirely independent data sets, this coincidence gives additional confidence in the results.

The results therefore appear to indicate that there was significant intra-seasonal variability of both diurnal and semidiurnal tides over the two sites and that, at least over the spatial scales considered here, it had similar spectral composition.

\subsection{Day-to-day variability of neutral wind and tides}

As discussed in Sect. 1, it has been suggested that the variability of tides in the MLT region may include a significant contribution from the non-linear interaction of the tides with planetary waves. In order to investigate this process a number of techniques have been used, including bispectral analysis (e.g. Rüster 1992, 1994; Clark and Bergin, 1997; Kamalabadi et al., 1997; Beard et al., 1999a, Pancheva, 2000). Here we will not directly investigate this mechanism further, but rather will apply a cross-wavelet analysis to the time series of tidal amplitudes over the UK and Bulgaria to measure the strength and time of occurrence of any oscillations in tidal amplitude which are simultaneously present over both sites. This allows an investigation of the degree to which such variability remains coherent over the spacing between the two radars. A similar analysis applied to the mean winds is used to investigate those large-scale components of the motion field (i.e. planetary waves) that may be related to the tidal variability through the mechanisms discussed already.

The cross-wavelet spectrum is a complex quantity where the modulus (i.e. the cross-wavelet power) at a particular frequency provides qualitative information about the strength of the oscillation present in each time series and the argument of the cross-wavelet spectrum describes the phase difference between the oscillations in each time series. In all the cross-wavelet analysis, no data from the period October 24-November 20, 1991 is considered because of poor data quality. As was mentioned before we would like to study in detail the strength and time of occurrence of any oscillations in neutral wind and in tidal amplitudes which are simultaneously present over both sites. However, as the neutral wind and tidal variability in each site are investigated in detail separately and results are presented for UK and Bulgaria respectively in Beard et al., (1999b) and in Pancheva and Mukhtarov (2000), we have to underline here that the significance of all discussed later oscillations present over both sites is higher than $95 \%$ confidence level.
Figure 6a presents a cross-wavelet power spectrum calculated from the hourly time series of zonal winds over Bulgaria and the UK. Figure $6 \mathrm{~b}$ presents the results of an identical analysis applied to the meridional winds. The large spatial scales of planetary waves in comparison to the spacing of the two radars means that these spectra are not very different from a mean of the spectra derived independently for each site (not shown). The contours are in arbitrary units related to the crosswavelet modulus, and so provide a qualitative indication of the large spatial-scale components of the MLT-region winds. The large values of the cross-wavelet modulus reflects the combined effects of large fluctuations of the signals in the both sites at this time and of a good matching of shape between the signal and the wavelet. The figures are again presented in terms of period rather than frequency to aid interpretation. A detailed discussion of the planetary-wave field revealed by this analysis is to be presented in a future work and so only a few particular features of interest will be detailed here.
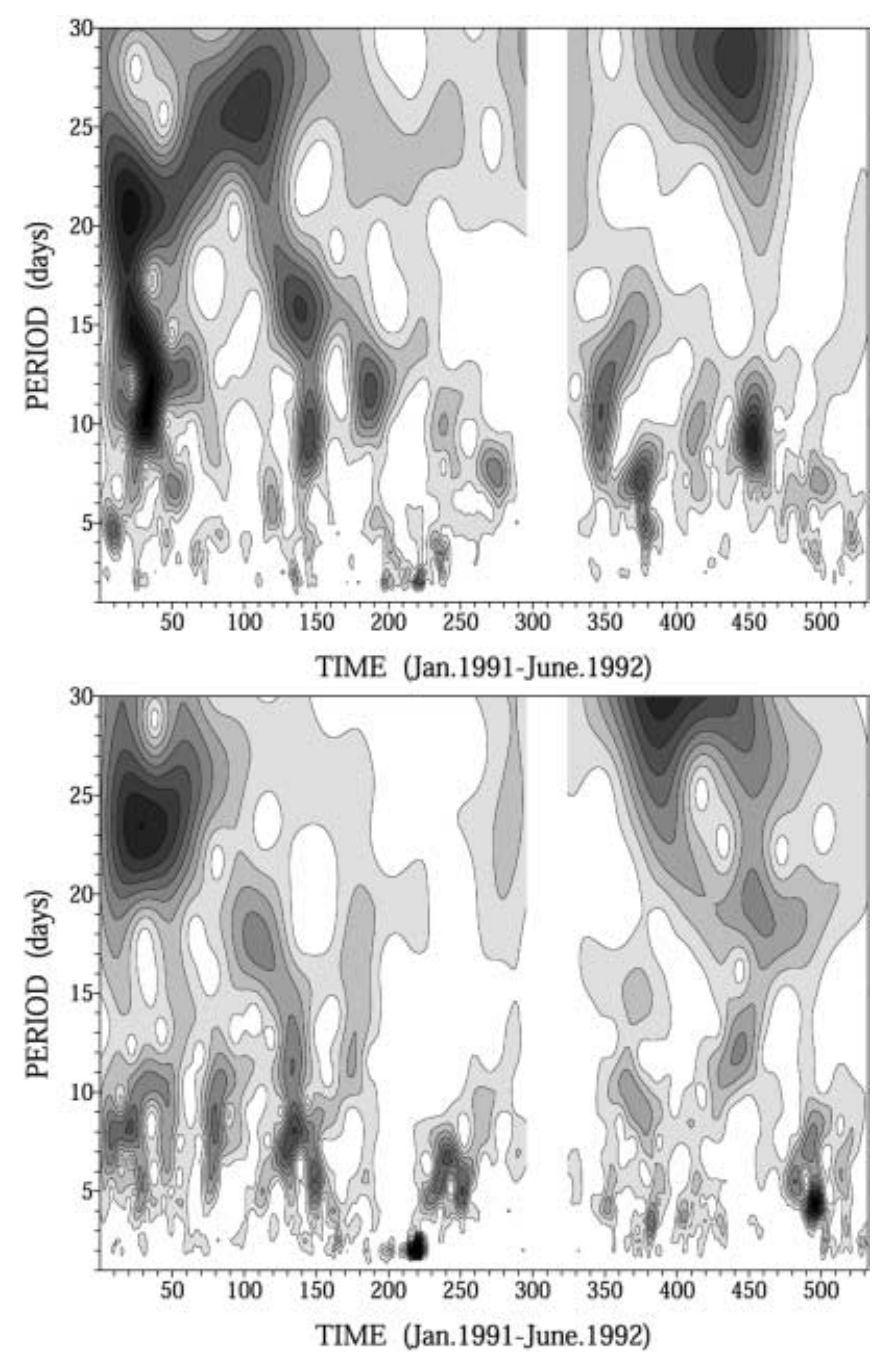

Fig. 6a, b. The cross-wavelet spectrum obtained from hourly values of the winds measured over Bulgaria and UK, a zonal winds, b meridional winds. The contours are in arbitrary units 
The cross-wavelet spectrum of zonal winds (Fig. 6a) shows that the winter months are dominated by many "bursts" of activity over a range of wavelet periods from about two days to more than 25 days. The bursts seldom last more than 30 days. Pancheva and Mukhtarov (1994) related at least some of these bursts to the major stratospheric warming event of January 1991. Activity at long periods is also apparent between day numbers 130-150, and may be related to the spring/summer transition in the flow. In the summer, activity is generally at shorter periods, particularly near two days and 5-10 days. The cross-wavelet spectrum of the meridional winds is shown in Fig. 6b. The general pattern is the same as for the zonal wind, although the strength of the response during the major stratospheric warmings and spring/summer transitions is not as strong.

Figure $7 \mathrm{a}$ presents the cross-wavelet spectrum of the zonal amplitudes of the semidiurnal tides calculated from the hourly time series of tidal amplitudes for each
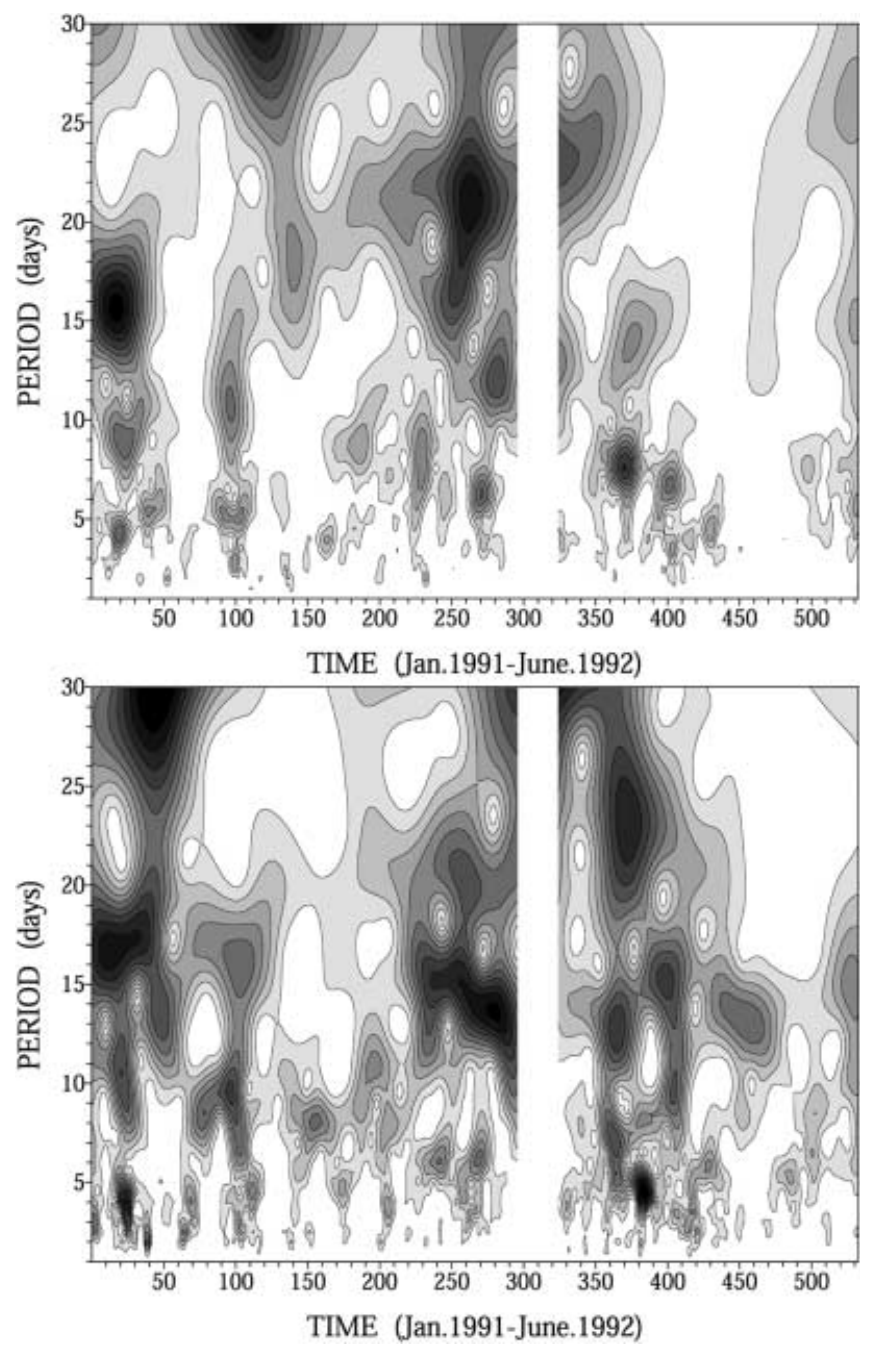

Fig. 7a, b. The cross-wavelet spectrum obtained from hourly values of the semidiurnal tidal amplitudes measured over Bulgaria and UK, a zonal components, b meridional component. The contours are in arbitrary units site. The equivalent analysis for the meridional component of the semidiurnal tide is presented in Fig. 7b. In the figures, a non-zero response indicates periodic modulation of the tidal amplitudes occurring simultaneously over both sites.

Considering the cross-wavelet analysis of zonal components shown in Fig. 7a, it is evident that there are a number of peaks at periods suggestive of planetary waves, particularly in the winter months. Some, but not all, of the peaks can be related to similar features in the cross-wavelet analysis of the zonal winds (Fig. 6a). In particular, during day numbers $1-50$ of 1991 , there is evidence of semidiurnal tidal amplitude fluctuations at periods of approximately 5, 10 and 15 days that correspond to features present in Fig. 6a. Similar coincidence is evident at a period of about nine days near day number 240 , a period near seven days at about day number 270 , a period near seven days at about day number 370 and a number of short events throughout the year at a period near two days. A notable feature is the activity at periods of about 2, 5, 11 and 30 days which occurs near day number 100 , coinciding with the final stratospheric warming in 1991 (Fig. 1a). However, it should also be noted that a number of conspicuous peaks in Fig. 7a have no counterpart in Fig. 6a and vica versa. Examples include the peak at a period near 20 days occurring near day number 260 in Fig. $7 \mathrm{a}$ and the strong peaks at periods of about 9, 12 and 16 days occurring between day numbers 140-200 in Fig. 6a. The data for the meridional semidiurnal component (Fig. 7b) display generally similar patterns to the zonal component (Fig. 7a), with the activity at longer periods again being greater in the winter months.

The results of an identical cross-wavelet analysis applied to the time series of diurnal tidal amplitudes at each site is presented in Fig. 8a, b for the zonal and meridional wind components of the tide, respectively. The general pattern of behaviour is less clear than for the semidiurnal tides. This may in part simply reflect the lower amplitudes of the diurnal tides. It should also be noted that some observational case studies have suggested that non-linear tidal/planetary-wave interactions are weaker in the case of the diurnal tide (e.g. Beard et al., 1999a).

\subsection{Planetary wave zonal wave numbers}

As discussed in Sect. 2, the cross-wavelet analysis reveals the phase difference between oscillations simultaneously present in each time series. The zonal wave number of particular planetary waves can thus be estimated from the time series of winds given the known $30.5^{\circ}$ longitudinal spacing of the sites, if the latitudinal separation of the two sites is small compared to the meridional wavelengths of the waves. In the following, the $12^{\circ}$ latitudinal spacing is assumed small enough that there are no appreciable phase changes over this distance. The zonal wave number, $k$, was then simply calculated from the observed phase difference using the relationship: $k=(360 / \Delta \lambda)(\Delta T / T)$, where $\Delta \lambda$ is the lon- 

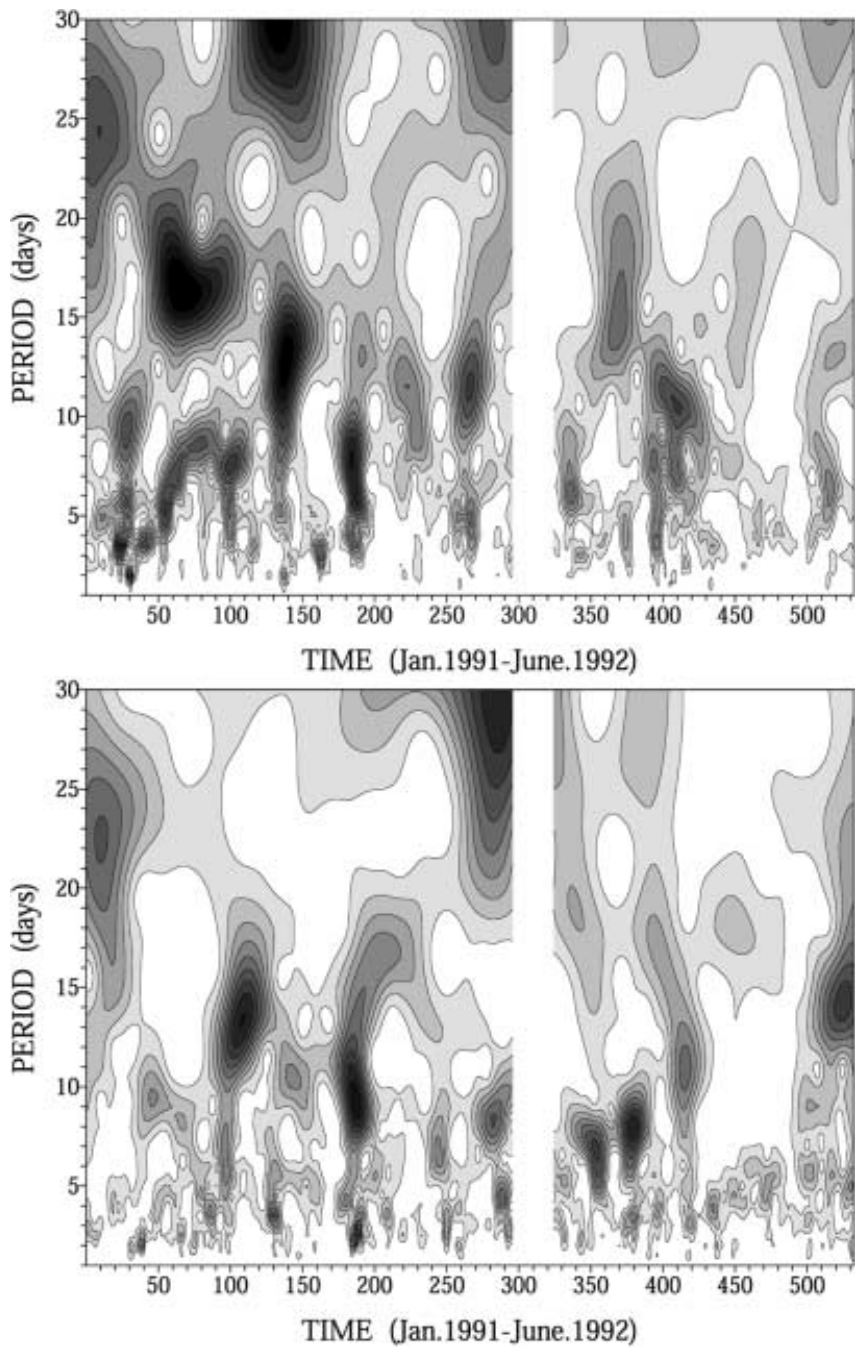

Fig. 8a, b. The cross-wavelet spectrum obtained from hourly values of the diurnal tidal amplitudes measured over Bulgaria and UK, a zonal components, b meridional component. The contours are in arbitrary units

gitudinal difference between the sites in degrees, $T$ is the wave period and $\Delta T$ is the phase difference between the two sites (Muller and Nelson, 1978).

The analysis was restricted to the most clearly defined waves. These were: (1) the wave of period near 11-days observed during January-February 1991; (2) a number of bursts of 2-day wave activity observed throughout the data set, and (3) a wave of period about 4-5 days observed in May 1992.

The wave activity at period near 11 days apparent during January-February 1991 (Fig. 6a) reached peak amplitudes of about $8 \mathrm{~m} \mathrm{~s}^{-1}$ over Bulgaria and about $15 \mathrm{~m} \mathrm{~s}^{-1}$ over the UK. The phase difference between the two sites was found to be 1.05 days, and to indicate a westward propagation. This yields a zonal wave number of $k=1.13$, which we take as indicating a zonal wave number $k=1$.

The zonal wind data for 1991 in Fig. 6a indicate three episodes of appreciable 2-day wave activity over both sites: during late January-February (approximate day numbers 20-35), May (day numbers 130-150) and July-August (day numbers 200-240). During JanuaryFebruary, 1991 the amplitudes reached $8 \mathrm{~m} \mathrm{~s}^{-1}$ over Bulgaria and $16 \mathrm{~m} \mathrm{~s}^{-1}$ over the UK. The dominant period of oscillation was $52 \mathrm{~h}$ and the observed phase difference was $17 \mathrm{~h}$, yielding a westward propagation and a zonal wave number, $k=3.86$, which we take to indicate an actual zonal wave number of 4 .

In the second episode (May), the period was nearer $52 \mathrm{~h}$ and the amplitudes over Bulgaria and the UK reached $7 \mathrm{~m} \mathrm{~s}^{-1}$ and $20 \mathrm{~m} \mathrm{~s}^{-1}$, respectively. In this case the phase difference was measured to be $14 \mathrm{~h}$, corresponding to a westward propagating disturbance of zonal wave number, $k=3.06$, which we take to indicate an actual wave number of 3 . In the third episode of 2 day wave activity (July-August), the phase was found to be most stable during day numbers 220-230, when the wave had a period of $48 \mathrm{~h}$ and amplitudes reached $14 \mathrm{~m} \mathrm{~s}^{-1}$ over Bulgaria and $28 \mathrm{~m} \mathrm{~s}^{-1}$ over the UK. For this interval, the phase difference was found to be $13 \mathrm{~h}$, indicating a westward propagating wave number $k=3.19$, which we take to indicate an actual wave number of 3 . Analysis of the meridional winds for these three events yielded similar results.

The final feature considered is the burst of wave activity with a period near four days, prominent in the meridional winds during May 1992 (Fig. 6b, day numbers about 485-500). The wave had slightly different periods over Bulgaria $(105 \mathrm{~h})$ and the UK $(96 \mathrm{~h})$, so the analysis is based on a representative period of $100 \mathrm{~h}$. The wave amplitudes were quite large, reaching $10 \mathrm{~m} \mathrm{~s}^{-1}$ over Bulgaria and $15 \mathrm{~m} \mathrm{~s}^{-1}$ over the UK. The calculated phase difference is $18 \mathrm{~h}$, yielding a westward propagating disturbance of zonal wave number, $k=2.12$, which we take to indicate an actual zonal wave number of 2 . The error in wave number introduced by the differing wave periods over the two sites is only about $+/-0.1$, and so the zonal wave number of 2 is still plausible.

\section{Discussion}

The general behaviour of the diurnal and semidiurnal tides presented in Sect 3.1 appears to be in good general agreement with empirical and theoretical models (e.g. Forbes and Vial, 1989). The similarities in the spectra of tidal amplitude and phase time series (Figs. 4a, b, 5a, b), particularly for the meridional components (Fig. 5a, b), suggest that much of the intra-seasonal variability on time scales from $30-80$ days occurs over spatial scales larger than the spacing of the two sites considered here. A number of explanations have been proposed to account for such observed variability of atmospheric tides, including fluctuations in the driving of the tide caused by variations in ozone/water-vapour distributions and wave set-up times (e.g. Vial, 1993).

There is now a considerable body of evidence from observation and theory to suggest that planetary waves and tides can undergo a non-linear interaction that 
results in periodic modulation of the tidal amplitude (e.g. Teitelbaum and Vial, 1991; Rüster 1992, 1994; Mitchell et al., 1996; Clark and Bergin, 1997; Kamalabadi et al., 1997; Beard et al., 1999a; Pancheva, 2000). The results presented in Sect. 3.2 suggest that this process has an intermittent character. There appear to be cases where strong planetary wave fluctuations are present over both sites, but no periodic modulation of the tidal amplitudes occurs. There are also episodes where the cross-wavelet spectra of the tidal amplitudes suggest modulation (e.g. the strong feature with a period of about 15 days near day numbers $220-280$ in Fig. 7b), but no planetary-wave signal is apparent in the wind data. Such features may be caused by interaction with planetary waves trapped at lower heights imprinting their periodicity on the ascending tides, which are then observed at MLT-region heights.

The wave number analysis of Sect. 3.3 yielded a zonal wave number 3 for two of the 2-day wave events, in agreement with that commonly reported. The zonal wave number of 4 determined for the case of JanuaryFebruary 1991 is more unusual. It should be noted that the GCM modelling study of Norton and Thuburn (1996) suggested that the 2-day wave sometimes can exhibit a zonal wave number of 4 or even higher. Observational studies have also sometimes reported a zonal wave number of 4 (Meek et al., 1996) or even 5 (Thayaparan et al., 1997). However, in the absence of a more extensive longitudinal series of observations than available here, our observation must remain tentative.

\section{Conclusions}

Observations of the MLT meteor region made with meteor radars in Bulgaria and the UK have been used to measure mean winds, tides and planetary waves over the period January 1991 to June 1992. Comparisons of the data recorded by the two instruments have been used to investigate some aspects of the temporal and spatial variability of the diurnal and semidiurnal tides.

The cross-wavelet spectra of zonal and meridional winds essentially reveal the planetary wave and tidal contributions to the large-scale motion field. The planetary wave field is dominated by short bursts of wave activity seldom lasting more than 30 days. At least one episode of strong wave activity appears to be connected to the final stratospheric warming of spring 1991.

The amplitude and phase of the diurnal and semidiurnal tides exhibit a clear seasonal course superposed on which are distinct fluctuations on all time scales considered from about 2-80 days. A major part of the power is concentrated in the 30-80 day intra-seasonal amplitude fluctuations, which can be as large as $300 \%$. The spectra of time series of amplitude and phase are very similar for the two sites, suggesting that the processes responsible for the fluctuations are of larger scale than the spacing between the sites $\left(30.5^{\circ}\right.$ of longitude, $12^{\circ}$ of latitude). Further studies using an extended network of instruments will be necessary to determine if such fluctuations are actually global in scale.
Cross-wavelet analysis applied to the tidal amplitude time series for the two sites has been used to investigate the spatial scale of periodic modulations in tidal amplitude that might arise from non-linear interaction with planetary waves. The spectra indicate that such modulation does sometimes occur simultaneously over the two sites, particularly in the case of the semidiurnal tide. However, the occurrence of such modulation is not always accompanied by a planetary wave of the appropriate period. This may indicate that the planetary wave/tidal interaction occurred at a lower height. There are also instances when strong planetary wave activity does not seem to result in a modulation of the tides.

Zonal wave numbers for a number of large amplitude planetary waves were determined from the phase difference in the wave observed over the two sites. A conspicuous oscillation with a period near 11 days observed during January-February 1991 had zonal wave number 1 . A wave of period near 4 days observed in May 1992 had zonal wave number 2. Three separate episodes of 2-day wave activity were analysed. Two of these (May 1991, July-August 1991) yielded a zonal wave number of 3. However, during January-February 1991 the 2-day wave appeared to exhibit zonal wave number 4 . All the disturbances were westward propagating. The possibility of alternative zonal structures for a wave of such large amplitude as the 2-day wave suggests that further investigations are needed to characterise this behaviour.

Acknowledgements. Topical Editor D. Murtagh thanks C. Jacobi for his help in evaluating this paper.

One of the authors (D.P.) is grateful to PPARC for support.

\section{References}

Beard, A. G., N. J. Mitchell, P. J. S. Williams, and M. Kunitake, Nonlinear interactions between tides and planetary waves resulting in periodic tidal variability, J. Atmos. Sol.-Terr. Phys., 61, 363-376, 1999a.

Beard, A. G., P. J. S. Williams, N. J. Mitchell, and H. G. Muller, Mean winds, tides and tidal variabilty in the lower thermosphere at $53.5^{\circ} \mathrm{N}, 3.9^{\circ} \mathrm{W}$ between 1990 and 1994, J. Atmos. Sol.Terr. Phys., (in press), 1999b.

Clark, R. R., and J. Bergin, Bispectral analysis of mesosphere wind, J. Atmos. Sol.-Terr. Phys., 59, 629-639, 1997.

Daubechies, I., The wavelet transform, time-frequency localization and signal analysis, IEEE Trans. Inf. Theory, 36(5), 961-1005, 1990.

Deng, W., J. E. Salah, R. R. Clark, S. J. Franke, D. C. Fritts, P. Hoffmann, D. Kuershner, A. H. Manson, C. E. Meek, D. Murphy, T. Nakamura, S. E. Palo, D. M. Riggin, R. G. Roble, R. Schminder, W. Singer, T. Tsuda, R. A.Vincent, and Q. Zhou, Coordinated global radar observations of tidal and planetary waves in the mesosphere and lower thermosphere during January 20-30, 1993, J. Geophys. Res., 102, 7307-7318, 1997.

Farge, M., Wavelet transforms and their applications to turbulence, Ann. Rev. Fluid Mech., 24, 395-457, 1992.

Forbes, J. M., The lower thermosphere coupling study of the CEDAR and WITS programs, Adv. Space Res., 10(6), 251-259, 1990.

Forbes, J. M., and F. Vial, Monthly simulation of the solar semidiurnal tide in the mesosphere and lower thermosphere, J. Atmos. Terr. Phys., 51, 649-661, 1989. 
Jacobi, C., R. Schminder, and D. Kürschner, Non-linear interaction of the quasi-2-day wave and long-term oscillations in the summer midlatitude mesopause region as seen from LF D1 wind measurements over Central Europe $\left(\right.$ Collm, $\left.52^{\circ} \mathrm{N}, 15^{\circ} \mathrm{E}\right)$, J. Atmos. Sol.-Terr. Phys., 60, 1175-1191, 1998.

Kamalabadi, F., J. M. Forbes, N. M. Makarov, and Y. I. Portnyagin, Evidence for nonlinear coupling of planetary waves and tides in the Antarctic mesopause, J. Geophys. Res., 102, 4437-4446, 1997.

Kopecky, M., and G. Kuklin, About 11-year variation of the mean life duration of a group solar spots, Issled. Geomagn. Aeronom. Fiz. Solntsa, 2, 167, 1971.

Manson, A. H., R. R. Clark, C. G. Fesen, J. M. Forbes, R. M. Johnson, S. Miyahara, J. E. Salah, and W. Singer, The mesosphere lower thermosphere coupling study, in Low latitude ionospheric physics, COSPAR, 7, pp. 339-348, Pergamon, New York, 1994.

Manson, A., C. Meek, M. Hagan, C. Hall, W. Hocking, J. MacDougall, S. Franke, D. Riggin, D. Fritts, R. Vincent, and M. Burrage, Seasonal variations of the semi-diurnal and diurnal tides in the MLT: multi-year MF radar observations from $2^{\circ}$ to $70^{\circ} \mathrm{N}$, and the GSWM tidal model, J. Atmos. Sol. Terr. Phys., 61, 809-828, 1999.

Meek, C. E., A. H. Manson, S. J. Franke, W. Singer, P. Hoffmann, R. R. Clark, T. Tsuda, T. Nakamura, M. Tsutsumi, M. Hagan, D. C. Fritts, J. Isler, and Y. I. Portnyagin, Global study of Northern Hemisphere quasi-2-day wave events in recent summers near $90 \mathrm{~km}$ altitude, J. Atmos. Terr. Phys., 58, 1401-1411, 1996.

Mitchell, N. J., P. J. S. Williams, A. G. Beard, G. Buesnel, and H. G. Muller, Non-linear planetary/tidal wave interactions in the lower thermosphere observed by meteor radar, Ann. Geophysicae, 14, 364-366, 1996.

Mukhtarov, P., and D. Pancheva, A new approach in studing the neutral wind and tides, Comp. Rend. Bulg. Acad. Sci., 46, 59-62, 1993.

Muller, H. G., and L. Nelson, A travelling quasi-2-day wave in the meteor region, J. Atmos. Terr. Phys., 40, 761-766, 1978.

Naujokat, B., K. Labitzke, R. Lenschow, K. Petzold, B. Rajewski, and R.-C. Wohlfard, The stratospheric winter 1990/91: a major midwinter warming as expected, Beil. Berliner Wetterkarte, SO 13/91, 1991.

Naujikat, B., K. Petzold, K. Labitzke, R. Lenschow, B. Rajewski, M. Wiesner, and R.-C. Wohlfart, The stratospheric winter 1991/ 92: The winter of the European Arctic stratospheric ozone experiment, Beil. Berliner Wetterkarte, SO 18/92, 1992.

Norton, W. A., and J. Thuburn, The two-day wave in a middle atmosphere GCM, Geophys. Res. Lett., 23, 2113-2116, 1996.

Pancheva, D., Evidence for non-linear coupling of planetary waves and tides in the lower thermosphere over Bulgaria, J. Atmos. Sol.-Terr. Phys., 62, 115-132, 2000.
Pancheva, D., and P. Mukhtarov, Variability of mesospheric dynamics observed at Yambol $\left(42.5^{\circ} \mathrm{N}, 26.6^{\circ} \mathrm{E}\right)$ by meteor radar, J. Atmos. Terr. Phys., 56, 1271-1278, 1994.

Pancheva, D., and P. Mukhtarov, Seasonal model of the dynamical regime in the upper mesosphere above Bulgaria, Bulg. Geophys. J., 22, 31-41, 1996.

Pancheva, D., and P. Mukhtarov, Wavelet analysis of transient behaviour of tidal amplitude fluctuations observed by meteor radar in the lower thermosphere above Bulgaria, Ann. Geophysicae, 18, 316-331, 2000.

Pancheva, D., A. G. Beard, N. J. Mitchell, and H. G. Muller, Nonlinear interactions between planetary waves in the mesosphere/ lower-thermosphere region, J. Geophys. Res., 105, A1, 157-170, 2000.

Portnyagin, Y. I., N. A. Makarov, R. P. Chebotarev, A. M. Nikonov, E. S. Kazimirovsky, V. D. Kokourov, V. V. Sidorov, A. N. Fahrutdinova, G. Cevolani, R. R. Clark, D. Kurschner, R. Schminder, A. H. Manson, C. E. Meek, H. G. Muller, J. C. Stoddart, W. Singer, and P. Hoffmann, The wind regime of the mesosphere during the DYANA campaign - II. Semidiurnal tide, J. Atmos. Terr. Phys., 56, 1731-1752, 1994.

Teitelbaum, H., and F. Vial, On tidal variability induced by nonlinear-interaction with planetary-waves, J. Geophys. Res., 96, 14 169-14 178, 1991.

Thayaparan, T., W. K. Hocking, J. MacDougall, A. H. Manson, and C. E. Meek, Simultaneous observations of the 2-day wave at London (43 degrees N, 81 degrees W) and Saskatoon (52 degrees N, 107 degrees W) near $91 \mathrm{~km}$ altitude during the two years of 1993 and 1994, Ann. Geophysicae, 15, 1324-1339, 1997.

Vial, F., Causes of tidal variability, in Coupling processes in the lower and middle atmosphere, Eds. E. V. Thrane, A. B. Blix, and D. C. Fritts, NATO ASI series, Kluwer Academic Publishers, 1993.

Rüster, R., VHF radar observations in the summer polar mesosphere indicating non-linear interaction, Adv. Space Res., 12, 85-88, 1992.

Rüster, R., VHF radar observations of nonlinear interactions in the summer polar mesosphere, J. Atmos. Terr. Phys., 56, 12891299, 1994.

Singer, W., P. Hoffmann, A. H. Manson, C. E. Meek, R. Schminder, D. Kurschner, G. A. Kokin, A. K. Knyazev, Y. I. Portnyagin, N. A. Makarov, A. N. Fahrutdinova, V. V. Sidorov, G. Cevolani, H. G.Muller, E. S. Kazimirovsky, V. A. Gaudikov, R. R. Clark, R. P. Chebotarev, and Y. Karadjaev, The wind regime of the mesosphere and lower thermosphere during the DYANA campaign - I: prevailing winds, J. Atmos. Terr. Phys., 56, 1717-1729, 1994.

Torrence, C., and G. Compo, A practical guide to wavelet analysis, Bull. Am. Meteorol. Soc., 79, 61-78, 1998.

Wernik, A. W., Methods of data analysis for resolving nonlinear phenomena, in Modern ionospheric science, Eds. H. Kohl, R. Ruster and K. Schlegel, European Geophysical Society, Katlenburg-Lindau, 322-345, 1996. 